\title{
World Ocean Isopycnal Level Absolute Geostrophic Velocity (WOIL-V) Inverted from GDEM with the P-Vector Method
}

\author{
Peter C. Chu \\ Naval Ocean Analysis and Prediction (NOAP) Laboratory, Department of Oceanography, \\ Naval Postgraduate School, Monterey, CA 93943, USA; pcchu@nps.edu
}

Received: 28 September 2017; Accepted: 2 January 2018; Published: 7 January 2018

\begin{abstract}
Three-dimensional dataset of world ocean climatological annual and monthly mean absolute geostrophic velocity in isopycnal level (called WOIL-V) has been produced from the United States (U.S.) Navy's Generalized Digital Environmental Model (GDEM) temperature and salinity fields (open access from the website http://data.nodc.noaa.gov/cgi-bin/iso?id=gov.noaa.nodc: 9600094) using the P-vector method. The data have horizontal resolution of $0.5^{\circ} \times 0.5^{\circ}$, and 222 isopycnal-levels. The total 13 data files include annual and monthly mean values. The WOIL-V is the only dataset of absolute geostrophic velocity in isopycnal level compatible to the GDEM $(T, S)$ fields, and provides background ocean currents for oceanographic and climatic studies, especially in ocean modeling with the isopycnal coordinate system.
\end{abstract}

Dataset: Global Identifier: 6274; Local Identifier: 1048ISOPYCNAL_GDEM_PVECTOR. Creator: NOAP Laboratory, Department of Oceanography, Naval Postgraduate School, Monterey, CA, USA. Title: World Ocean Isopycnal-Level Velocity Inverted from GDEM with the P-Vector Method. Publisher: British Oceanographic Data Centre, United Kingdom. Publication year: 2014. https: //www.bodc.ac.uk/data/information_and_inventories/edmed/report/6274/.

Dataset License: BODC Data Policy, "data may be held in either analogue or digital form and be stored either on paper or a variety of computer-compatible media; physical specimens in curated collections are outside the usual sense of the word".

Keywords: isopycnal level; world ocean geostrophic velocity; GDEM; P-vector method; climatology

\section{Introduction}

Since ocean is generally adiabatic and statically stable, the potential density is conserved, increases monotonically with depth, and serves as a useful vertical coordinate. In the isopycnal coordinate system, explicit advection acts only in the horizontal. This makes the ocean models to avoid numerical diffusion in the vertical that can be troublesome in other vertical coordinate systems, such as z-coordinate and terrain-following coordinate. The isopycnal coordinate is often used in ocean modeling and prediction such as in the Hybrid Coordinate Ocean Model (HYCOM) (https:/ /hycom.org/, for example [1,2]).

Generalized Digital Environmental Model (GDEM), produced by the Naval Oceanographic Office (Hancock County, MS, USA) and published by the NOAA National Centers for Environmental Information (NCEI) (Asheville, NC, USA) (http:/ / data.nodc.noaa.gov/cgi-bin/iso?id=gov.noaa.nodc: 9600094), contains gridded $\left(0.5^{\circ} \times 0.5^{\circ}\right)$ annual and monthly means of temperature $(T)$, salinity (S) [3]. The GDEM is comparable to a more widely quoted $(T, S)$ climatological data, the World Ocean Atlas (WOA), which is produced by NOAA/National Centers for Environmental Information (NECI). 
Large-scale oceanographic features are similar in DGEM and WOA [4]. Since the 3D gridded $(T, S)$ fields are similar between GDEM and WOA, the absolute geostrophic velocity fields are comparable calculated from GDEM and WOA using the same P-vector method.

However, an important variable, ocean current velocity vector $(u, v)$, is not included in the GDEM dataset. This is primary due to the lack of velocity observations, which are difficult and costly to make. Ocean models, including HYCOM, are generally integrated from known $\left(T_{\text {in }}, S_{\text {in }}\right)$ and zero velocity fields, while holding $\left(T_{\mathrm{in}}, S_{\text {in }}\right)$ unchanged, which is called the diagnostic run. After a period of the diagnostic run (i.e., spin-up), the velocity field $\left(\mathbf{V}_{\text {in }}\right)$ is established, and ( $\left.T_{\text {in }}, S_{\text {in }}, \mathbf{V}_{\text {in }}\right)$ fields are then treated as the initial conditions for the prognostic numerical modeling. Such a diagnostic initialization artificially adds extremely strong thermohaline sources and sinks into the ocean and far from realistic [5]. Thus, construct of isopycnal-level ocean current velocity data is important for climatic and oceanographic studies using the isopycnal coordinate ocean models, such as HYCOM.

Climatological annual and monthly mean gridded absolute geostrophic velocity data on z-level, computed from the NOAA/NCEI World Ocean Atlas (WOA) $(T, S)$ fields to represent the large-scale ocean circulation using the P-vector method, was published at the NCEI website: http:/ / data.nodc. noaa.gov/cgi-bin/iso?id=gov.noaa.nodc:0121576 [6]. However, there is no such velocity data on isopycnal level. To fill the gap, climatological annual and monthly mean gridded $\left(0.5^{\circ} \times 0.5^{\circ}\right)$ absolute geostrophic velocity data on 222 isopycnal levels are calculated from the GDEM $(T, S)$ data using the P-vector inverse method $[7,8]$. This velocity dataset is called the World Ocean Isopycnal Level Absolute Geostrophic Velocity (WOIL-V).

\section{Data Production Method}

\subsection{Theory}

Let $(x, y, \rho)$ be the coordinates with $x$-axis in the zonal direction (eastward positive), $y$-axis in the latitudinal direction (northward positive), and $\rho$-axis in the vertical (isopycnal level) with unit vectors $(\mathbf{i}, \mathbf{j}, \mathbf{k})$ in the three directions; and $\mathbf{V}=(u, v, 0)$, the velocity vector with the components in the three coordinate axes. The geostrophic balanced motion on an isopycnal level $(\rho)$ with pressure $(p)$ is given by $([9-11])$

$$
\mathbf{V}=\frac{1}{f} \mathbf{k} \times \nabla M,
$$

where $f$ is the Coriolis parameter; $M=p / \rho+g z$, is the Montgomery potential. The hydrostatic balance is written by

$$
\frac{p}{\rho^{2}}+\frac{\partial M}{\partial \rho}=0
$$

The adiabatic density conservation and incompressible continuity equations are combined to give an equation for the thickness, $\partial p / \partial \rho$. The continuity equation is given by

$$
\nabla \times\left(\frac{\partial p}{\partial \rho} \mathbf{V}\right)=0
$$

Note that the differentiations with respect to $x$ and $y$ are on the isopycnal surface. Differentiation of (1) with respect to $\rho$ and use of (2) lead to the thermal wind relation

$$
\frac{\partial \mathbf{V}}{\partial \rho}=-\frac{1}{f \rho^{2}} \mathbf{k} \times \nabla p
$$

The continuity Equation (3) can be rewritten by

$$
\mathbf{V} \times \nabla\left(\frac{\partial p}{\partial \rho}\right)+\frac{\partial p}{\partial z} \nabla \times \mathbf{V}=0
$$


Use of (1) yields

$$
\nabla \times \mathbf{V}=\nabla\left(\frac{1}{f}\right) \times(\mathbf{k} \times \nabla M)=-\frac{1}{f} \nabla f \times \mathbf{V} .
$$

Substitution of (6) into (5) yields the conservation of potential vorticity $(q)$ at the isopycnal level,

$$
\mathbf{V} \times \nabla q=0
$$

where

$$
q=\frac{f g}{\hat{h}^{(\sigma)}}
$$

and $\hat{h}^{(\sigma)}$ is the thickness between two adjacent isopycnal levels. The $(p, q)$ fields are computed at the isopycnal level can be computed numerically after the hydrographic data are processed in the isopycnal surface.

The potential vorticity conservation requires that any water particle moves along $q$-isoline on the isopycnal level, i.e., any $q$-isoline is a trajectory of water particles (Figure 1). For each trajectory, the $\mathrm{P}$-vector is defined as the unit tangential vector,

$$
\mathbf{P}=\frac{1}{|\nabla q|}(\mathbf{k} \times \nabla q)=\frac{1}{|\nabla q|}\left(-\frac{\partial q}{\partial y} \mathbf{i}+\frac{\partial q}{\partial x} \mathbf{j}\right) .
$$

Equation (9) shows that the existence of $\mathbf{P}$ requires

$$
\nabla q \neq 0
$$

At any point on the isopycnal level, the vector $\mathbf{P}$ indicates the tangential direction of the trajectory, and therefore, is parallel to the absolute velocity vector,

$$
\mathbf{V}=\gamma(x, y, \rho) \mathbf{P}
$$

where $\gamma$ is the speed parameter with $|\gamma|$ the speed of the absolute geostrophic velocity, i.e.,

$$
|\gamma|=|\mathbf{V}|
$$

Substitution of (11) into the thermal wind relation (4) leads to

$$
\frac{\partial \gamma}{\partial \rho} \mathbf{P}+\gamma \frac{\partial \mathbf{P}}{\partial \rho}=-\frac{1}{f \rho^{2}} \mathbf{k} \times \nabla p .
$$

Vector-product of both sides of (13) by the vector $\mathbf{P}$ gives

$$
\gamma\left(\mathbf{P} \times \frac{\partial \mathbf{P}}{\partial \rho}\right)=-\frac{1}{f \rho^{2}} \mathbf{P} \times(\mathbf{k} \times \nabla p) .
$$

Scalar-product of both sides of (14) by the vector $\mathbf{P}$ yields

$$
\gamma=\frac{\mathbf{P} \times \nabla p}{f \rho^{2} \mathbf{P} \times(\mathbf{k} \times \partial \mathbf{P} / \partial \rho)} .
$$

It is noted that $\gamma$-value calculated with (15) is noisy. A two-step method was proposed in the P-vector inverse method [7]: (a) determination of the unit vector P; and, (b) determination of the scalar $\gamma$ from the thermal wind relation,

$$
\gamma^{(k)} P_{x}^{(k)}-\gamma^{(m)} P_{x}^{(m)}=\Delta u_{k m}
$$




$$
\begin{gathered}
\gamma^{(k)} P_{y}^{(k)}-\gamma^{(m)} P_{y}^{(m)}=\Delta v_{k m} \\
\Delta u_{k m} \equiv \frac{1}{f} \int_{\rho_{m}}^{\rho_{k}} \frac{1}{\rho^{2}} \frac{\partial p}{\partial y} d \rho \\
\Delta v_{k m} \equiv-\frac{1}{f} \int_{\rho_{m}}^{\rho_{k}} \frac{1}{\rho^{2}} \frac{\partial p}{\partial x} d \rho
\end{gathered}
$$

where $\left(\Delta u_{k m}, \Delta v_{k m}\right)$ are geostrophic shear at isopycnal level $\rho_{k}$ relative to $\rho_{m}$. If the determinant of the two linear algebraic Equations (16) and (17) is non-zero,

$$
\sin \left(\Delta \alpha_{k m}\right)=\left|\begin{array}{ll}
P_{x}^{(k)} & P_{x}^{(m)} \\
P_{y}^{(k)} & P_{y}^{(m)}
\end{array}\right| \neq 0
$$

i.e., the $\mathbf{P}$ vector spiral [12] exists (Figure 2), the speed parameter $\gamma$ at these two levels $\gamma^{(k)}$ and $\gamma^{(m)}$ can be determined after solving the linear algebraic Equations (16) and (17), and, in turn, the horizontal velocity. This method was evaluated using the Modular Ocean Model [13] and applied to calculate the absolute velocity from hydrographic data for the South China Sea [10], Japan Sea [5,14] Northwest Pacific [15], and global oceans [16]. To reduce error due to uncertainty of the P-vector, a variational P-vector method was developed [14].

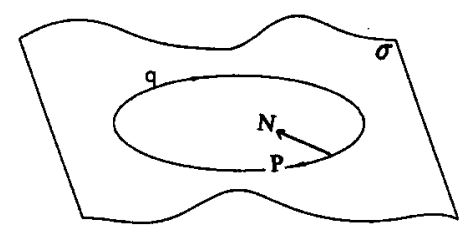

Figure 1. Isoline of potential vorticity $(q)$ is the trajectory on the isopycnal surface [12].

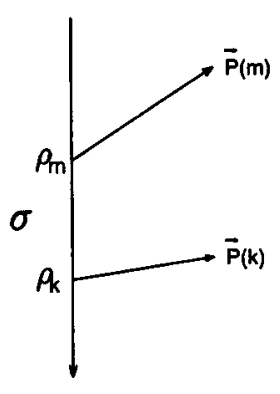

(a)

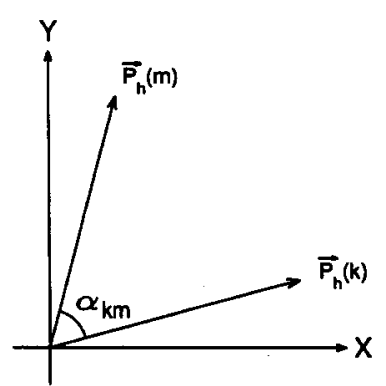

(b)

Figure 2. Illustration of (a) P-spiral and (b) turning angle (right panel) $\alpha_{k m}$ between two isopycnal levels.

\subsection{Numerical Calculation}

The potential density of seawater is a function of potential temperature $(\theta)$, salinity, and pressure, i.e., $\rho=\rho(S, \theta, p)$. The 222 isopycnal levels are determined through the discretization of

$$
\sigma_{\theta}=\rho(S, \theta, 0)-1000 \mathrm{~kg} \mathrm{~m}^{-3} .
$$

Since the minimum and maximum value of $\sigma_{\theta}$ computed from the $\operatorname{GDEM}(T, S)$ data set are 22.2 and $27.725 \mathrm{~kg} \mathrm{~m}^{-3}$, the discretization of $\sigma_{\theta}$ is by the increment of 


$$
\Delta \sigma=0.025 \mathrm{~kg} \mathrm{~m}^{-3} .
$$

Thus, we have $222 \sigma$-levels, i.e., $\sigma(1)=22.2 \mathrm{~kg} \mathrm{~m}^{-3}, \sigma(222)=27.725 \mathrm{~kg} \mathrm{~m}^{-3}$. Here, the homogeneous increment is used. For the area where isopycnal changes drastically, the isopycnal resolution should be increased. This will be in future studies.

The observational and climatological $(T, S)$ data (such as GDEM) are in the $z$-coordinate. In order to well resolve isopycnal surfaces, the cubic spline is used to interpolate the $T, S$ data into 222 z-levels with three different increments: $5 \mathrm{~m}$ from $0-\mathrm{m}$ to $100-\mathrm{m}$ depth, $10 \mathrm{~m}$ from 100-m to 1000-m depths, $20 \mathrm{~m}$ from $1000-\mathrm{m}$ to $2500-\mathrm{m}$ depths, and $50 \mathrm{~m}$ below 2500-m depths. Using (21), the dataset is given by $\left[T\left(z_{j}\right), S\left(z_{j}\right), \hat{\sigma}_{\theta}\left(z_{j}\right), j=1,222\right]$ in $z$-coordinate. The depth and isopycnal level are exchanged by [10]

$$
\hat{z}_{k}^{(\sigma)}=z_{j}+\frac{\sigma(k)-\hat{\sigma}_{\theta}\left(z_{j}\right)}{\hat{\sigma}_{\theta}\left(z_{j+1}\right)-\hat{\sigma}_{\theta}\left(z_{j}\right)}\left(z_{j+1}-z_{j}\right) \text { if } \hat{\sigma}\left(z_{j}\right)<\sigma^{b}(k)<\hat{\sigma}\left(z_{j+1}\right) .
$$

The thickness between $(k-1)$-th and $k$-th isopycnal levels is obtained by

$$
\hat{h}_{k}^{(\sigma)}=\hat{z}_{k-1}^{b}-\hat{z}_{k}^{b}
$$

After $\hat{h}_{k}^{(\sigma)}$ is obtained, we may compute potential vorticity $q$ using (8), and the P-vector using (9), and the absolute geostrophic velocity using (16)-(19).

\section{Data}

The WOIL-V dataset is in the Network Common Data Form (netCDF) (see the website: http: //www.unidata.ucar.edu/software/netcdf/), which is an interface for array-oriented data access, a library for implementation of interface, and a machine-independent format for representing data. The netCDF software was developed at the Unidata (http:/ / www.unidata.ucar.edu) Program Center in Boulder, Colorado. Each element is stored at a disk address which is a linear function of the array indices (subscripts) by which it is identified. Hence, these indices need not be stored separately (as in a relational database). This provides a fast and compact storage method. The external types that are supported by the netCDF interface are listed in Table 1 . These types are chosen to provide a reasonably wide range of trade-offs between data precision and number of bits required for each value. The external data types are independent from whatever internal data types are supported by a particular machine and language combination. These types of extracted data are called "external", because they correspond to the portable external representation for netCDF data.

Table 1. Extracted data type and characteristics.

\begin{tabular}{cc}
\hline Data Type & Characteristics \\
\hline char & 8-bit characters intended for representing text \\
byte & 8-bit signed or unsigned integers \\
short & 16-bit signed integers \\
int & 32-bit signed integers \\
Float/real & 32-bit IEEE floating-point \\
double & 64-bit IEEE floating-point \\
\hline
\end{tabular}

The WOIL-V dataset is for the global oceans. It is noted that the velocity data is questionable in the equatorial region $\left(5^{\circ} \mathrm{S}-5^{\circ} \mathrm{N}\right)$ since the geostrophic balance fails there. The velocity vectors in the northwestern Pacific in June at two isopycnal levels $\left(\sigma_{\theta}=23.5,25.0 \mathrm{~kg} \mathrm{~m}^{-3}\right)$ are used as examples for illustration (Figure 3). The data show the westward flowing North Equatorial Current (NEC), the northeast flowing Kuroshio Current $(\mathrm{KC})$, and the associated eddies and recirculation current from Kuroshio (RC), and the eastward flowing Subtropical Countercurrent (STCC). At $\sigma_{\theta}=23.5$ (Figure 3a), NEC is very weak. The eastward flowing STCC originates mainly from the southward turning of RC 
(westward flowing) at $\left(127^{\circ}-128^{\circ} \mathrm{E}, 23^{\circ} \mathrm{N}\right)$. At $\sigma_{\theta}=25.0$ (Figure $\left.3 \mathrm{~b}\right), \mathrm{NEC}$ is quite strong. Between $128^{\circ}-134^{\circ} \mathrm{E}$, a weak current flowing eastward along $21^{\circ} \mathrm{N}$ is the north flank of an anticyclonic eddy located at $18^{\circ}-21^{\circ} \mathrm{N}, 128^{\circ}-134^{\circ} \mathrm{E}$ (Figure $3 \mathrm{~b}$ ). The four meridional cross-sections $\left(127.5^{\circ} \mathrm{E}, 129.5^{\circ} \mathrm{E}\right.$, $133.5^{\circ} \mathrm{E}, 138.5^{\circ} \mathrm{E}$ ) of the east-west absolute velocities at isopycnal levels (Figure 4 ) clearly show the spatial variability. For example, the maximum velocity of STCC is around $4 \mathrm{~cm} \mathrm{~s}^{-1}$ near $20^{\circ} \mathrm{N}$ between $\sigma_{\theta}=23.0$ and $\sigma_{\theta}=24.0$ at $127.5^{\circ}$ E cross-section (Figure 4a); is greater than $6 \mathrm{~cm} \mathrm{~s}^{-1}$ near $21^{\circ} \mathrm{N}$ and $\sigma_{\theta}=24.2$ at $129.5^{\circ}$ E cross-section (Figure $4 \mathrm{~b}$ ); is greater than $9 \mathrm{~cm} \mathrm{~s}^{-1}$ near $21.5^{\circ} \mathrm{N}$ and $\sigma_{\theta}=24.3$ at $133.5^{\circ} \mathrm{E}$ cross-section (Figure 4c); and, is greater than $12 \mathrm{~cm} \mathrm{~s}^{-1}$ near $23^{\circ} \mathrm{N}$ and $\sigma_{\theta}=24.5$ at $138.5^{\circ} \mathrm{E}$ cross-section (Figure $4 \mathrm{~d}$ ). At the $\sigma_{\theta}$ level, where the core of STCC located, the speed of STCC is usually higher than the speed of NEC. Interested readers are referred to [10].
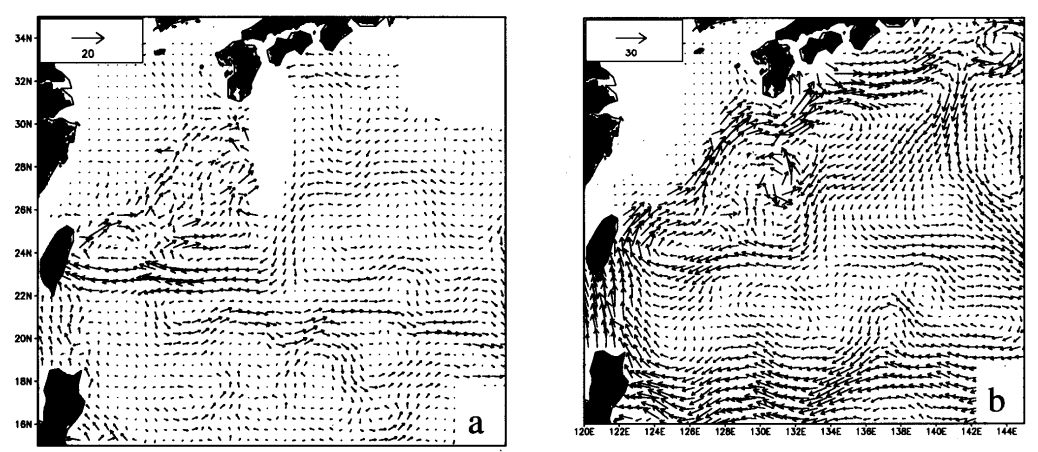

Figure 3. Absolute velocity vectors (unit: $\mathrm{cm} / \mathrm{s}$ ) in June on isopycnal surface (a) $\sigma_{\theta}=23.5 \mathrm{~kg} \mathrm{~m}^{-3}$; and (b) $\sigma_{\theta}=25.0 \mathrm{~kg} \mathrm{~m}^{-3}[10]$.
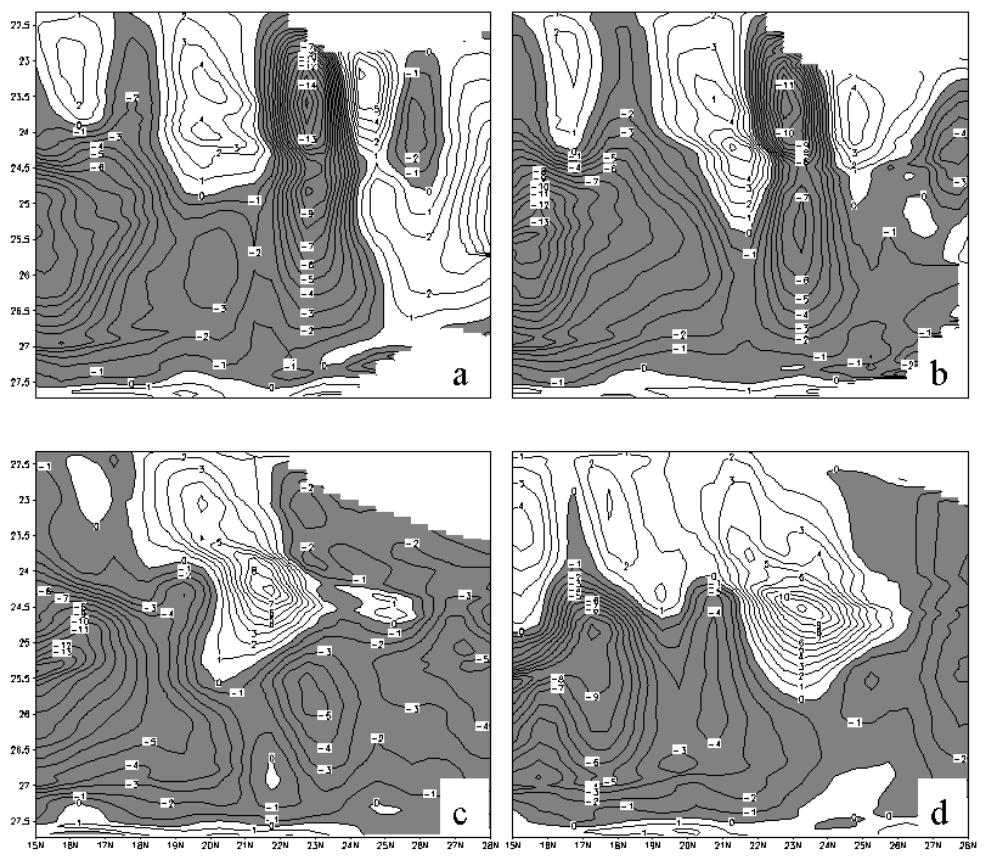

Figure 4. East-west absolute velocity (unit: $\mathrm{cm} / \mathrm{s}$ ) in June at meridional cross-sections: (a) $127.5^{\circ} \mathrm{E}$; (b) $129.5^{\circ} \mathrm{E}$; (c) $133.5^{\circ} \mathrm{E}$; and, (d) $138.5^{\circ} \mathrm{E}$. Here, the shaded part (negative values) refers to the westward velocity (from [10]).

\section{Data Download and User Notes}

The data can be downloaded directly from the BODC website: https:/ / www.bodc.ac.uk/data/ information_and_inventories/edmed/report/6274/. Please contact BODC Customer Service if you need further assistance (http://www.bodc.ac.uk/). The free netCDF package needs to be downloaded 
from the website: https://www.image.ucar.edu/GSP/Software/Netcdf/ before reading the data. The MATLAB (version 2008b and later) provides access to more than 30 functions in the netCDF interface. This interface provides an application program interface (API) that you can use to enable reading data from and writing data to netCDF files (known as datasets in netCDF terminology). The MATLAB code is listed as follows to read the data in netCDF.

$\%$ read the annual mean data as an example

ncid=netcdf.open('annual_isopycnal.nc','nowrite');

$\%$ get the longitude data

lon_id=netcdf.inqVarID(ncid,'lon');

lon=netcdf.getVar(ncid,lon_id);

$\%$ get the latitude data

lat_id=netcdf.inqVarID(ncid,'lat');

lat=netcdf.getVar(ncid,lat_id);

$\%$ get the sigma_level data s

s_id=netcdf.inqVarID(ncid,'sigma_level');

s=netcdf.getVar(ncid,s_id);

$\%$ get the zonal and meridional absolute geostrophic velocity data

u_id=netcdf.inqVarID(ncid,' $\left.u^{\prime}\right)$;

v_id=netcdf.inqVarID(ncid,' $\left.v^{\prime}\right)$;

$\%$ get the unit

units=netcdf.getAtt(ncid,u_id,'units');

$\%$ get the isopycnal level depth data

d_id=netcdf.inqVarID(ncid,'sigma_depth');

$\%$ get the unit

units=netcdf.getAtt(ncid,d_id,'units');

$\%$ get al.l the data

$\mathrm{u}=$ netcdf.getVar(ncid, $\mathrm{u} \_$id);

$\mathrm{v}=$ netcdf.get $\operatorname{Var}\left(\mathrm{ncid}, \mathrm{v} \_\mathrm{id}\right)$;

d =netcdf.getVar(ncid,d_id);

$\%$ get part of the data

$\%$ example: isopycnal level ' $k$ ' data

$\mathrm{u}=$ netcdf.getVar(ncid,u_id,[0,0,k-1,0],[344,720,1,1]);

$\mathrm{v}=$ netcdf.getVar(ncid,v_id,[0,0,k-1,0],[344,720,1,1]);

d=netcdf.getVar(ncid,d_id,[0,0,k-1,0],[344,720,1,1]);

$\%$ set the garbage data to $\mathrm{NaN}$.

$\mathrm{u}(\mathrm{u}>1 \mathrm{e} 30)=\mathrm{NaN} ; \mathrm{v}(\mathrm{v}>1 \mathrm{e} 30)=\mathrm{NaN}$;

$\%$ close the data file

netcdf.close(ncid);

\section{Summary}

The P-vector method was proposed two decades ago [7] and is described in detail in [8], however it is the first time to present its data product in isopycnal level, i.e., three-dimensional (3D) world ocean climatological annual and monthly mean absolute geostrophic velocity (called WOIL-V) computed from the GDEM temperature and salinity fields. The monthly varying 3D ocean general circulations in isopycnal level provide unique and realistic initial conditions of $(u, v)$ for isopycnal coordinate 
ocean models, such as HYCOM. Furthermore, the P-vector method can also be used to decompose the model current velocity into geostrophic and ageostrophic components since the absolute geostrophic currents can be calculated from 3D $(T, S)$ fields. Many oceanographic characteristics can be identified from the decomposition, such as geostrophic and ageostrophic transports and heat/salt budgets, and boundary currents.

Acknowledgments: Joana Beja De Almeida E Silva's outstanding efforts to publish this dataset at the BODC are highly appreciated. The Research Office of the Naval Postgraduate School supports the publication. The research presented in this paper was funded by the Office of Naval Research.

\section{Conflicts of Interest: None.}

\section{References}

1. Yuan, D.; Han, W. Roles of Equatorial Waves and Western Boundary Refelection in the Seasonal Circulation of the Equatorial Indian Ocean. J. Phys. Oceanogr. 2006, 36, 930-944. [CrossRef]

2. Sun, S.; Bleck, R. Geographic distribution of the diapycnal component of thermohaline circulations in coupled climate models. Ocean. Model. 2006, 15, 177-199. [CrossRef]

3. Allen, R.L., Jr.; US Navy; Naval Oceanographic Office. Global Gridded Physical Profile Data from the U.S. Navy's Generalized Digital Environmental Model (GDEM) Product Database (NODC Accession 9600094); Version 1.1; National Oceanographic Data Center, NOAA: Silver Spring, MD, USA. Available online: https:/ / data.nodc. noaa.gov/cgi-bin/iso?id=gov.noaa.nodc:9600094 (accessed on 2 February 2014).

4. Teague, W.J.; Carron, M.J.; Hogan, P. A comparison between the Generalized Digital Environmental Model and Levitus climatologies. J. Geophys. Res. 1990, 95, 7167-7183. [CrossRef]

5. Chu, P.C.; Lan, J.; Fan, C.W. Japan Sea circulation and thermohaline structure, Part 1 Climatology. J. Phys. Oceanogr. 2001, 31, 244-271. [CrossRef]

6. Chu, P.C.; Fan, C.W. Absolute geostrophic velocity inverted from World Ocean Atlas 2013 (WOAV13) with the P-vector method. Geosci. Data J. 2015. [CrossRef]

7. Chu, P.C. P-vector method for determining absolute velocity from hydrographic data. Mar. Technol. Soc. J. 1995, 29, 3-14.

8. Chu, P.C. P Vector Inverse Method; Springer: Berlin, Germany, 2006; pp. 1-605.

9. Chu, P.C.; Li, R.F. South China Sea isopycnal surface circulations. J. Phys. Oceanogr. 2000, 30, 2419-2438. [CrossRef]

10. Chu, P.C.; Li, R.F.; You, X.B. Northwest Pacific subtropical countercurrent on isopycnal surface in summer. Geophys. Res. Lett. 2002, 29. [CrossRef]

11. Chu, P.C.; Lan, J. Extremely strong thermohaline source/sinks generated by diagnostic initialization. Geophys. Res. Lett. 2003, 30. [CrossRef]

12. Chu, P.C. P-vector spirals and determination of absolute velocities. J. Oceanogr. 2000, 56, 591-599. [CrossRef]

13. Chu, P.C.; Fan, C.W.; Cai, W.J. Evaluation of P-vector method using modular ocean model (MOM). J. Oceanogr. 1998, 54, 185-198. [CrossRef]

14. Chu, P.C.; Lan, J.; Fan, C.W. Japan Sea circulation and thermohaline structure, Part 2 A variational P-vector method. J. Phys. Oceanogr. 2001, 31, 2886-2902. [CrossRef]

15. Chu, P.C.; Li, R.F.; Fan, C.W. Determination of the current system on isopycnal surface between Mindanao and New Guinea from GDEM. Chin. J. Oceanol. Limnol. 2003, 21, 193-213. [CrossRef]

16. Chu, P.C.; Fan, C.W. An inverse model for calculation of global volume transport from wind and hydrographic data. J. Mar. Syst. 2007, 65, 376-399. [CrossRef] 